\title{
Plastic changes in tadpole trophic ecology revealed by stable isotope analysis
}

\author{
Stéphane Caut • Elena Angulo • Carmen Díaz-Paniagua • \\ Ivan Gomez-Mestre
}

\begin{abstract}
Amphibian larvae constitute a large fraction of the biomass of wetlands and play important roles in their energy flux and nutrient cycling. Interactions with predators and competitors affect their abundance but also their foraging behaviour, potentially leading to non-consumptive cascading effects on the whole trophic web. We experimentally tested for plastic changes in larval trophic ecology of two anuran species in response to competitors and the non-lethal presence of native and non-native predators, using stable isotope analysis. We hypothesized that tadpoles would alter their diet in the presence of competitors and native predators, and to a lesser extent or not at all in the presence of non-native predators. First, we conducted a controlled diet experiment to estimate tadpole turnover rates and discrimination factors using Pelobates cultripes and Bufo calamita. Turnover rates yielded a half-life of 15-20 days (attaining a quasi-isotopic equilibrium after 2 months), whereas discrimination factors for natural controlled diets resulted in different isotopic values essential for calibration. Second, we did an experiment with $P$. cultripes and Rana perezi (=Pelophylax perezi) where we manipulated the presence/absence of predators
\end{abstract}

S. Caut $(\bowtie) \cdot$ E. Angulo · C. Díaz-Paniagua · I. Gomez-Mestre Estación Biológica de Doñana, CSIC, Avda. Americo Vespucio s/n, 41092 Sevilla, Spain

e-mail: stephanecaut@gmail.com

I. Gomez-Mestre

Research Group of Biodiversity (UO, CSIC, PA),

c/Catedrático Rodrigo Uría s/n, 33071 Oviedo, Spain and heterospecific tadpoles using microcosms in the laboratory. We detected a significant shift in trophic status of both amphibian species in the presence of non-native crayfish: the $\delta^{15} \mathrm{~N}$ values and macrophyte consumption of tadpoles increased, whereas their detritus consumption decreased. This suggests that tadpoles could have perceived crayfish as a predatory risk or that crayfish acted as competitors for algae and zooplankton. No dietary changes were observed in the presence of native dragonflies or when both tadpole species co-occurred. Stable isotopic analysis is an efficient way to assess variation in tadpoles' tropic status and hence understand their role in freshwater ecosystems. Here we provide baseline isotopic information for future trophic studies and show evidence for plastic changes in tadpoles' use of food resources under different ecological scenarios.

Keywords Discrimination factor - Turnover - Isotopic incorporation · Invasive species · Diet shift

\section{Introduction}

Species interactions can have large effects on community diversity, stability and productivity. In freshwater systems, loss of consumer diversity is occurring at an alarming rate, with profound ecological consequences (Whiles et al. 2010). Amphibian larvae are key consumers in a variety of freshwater systems, both lotic and lentic, where they can reach high densities and biomass, and also serve as important prey for a number of other species (Wells 2007; Schiesari et al. 2009). Larvae of most anuran species are herbivores that complement their diets with additional types of resources such as detritus, bacteria, plankton or fungi, and hence can be classified as opportunistic 
omnivores or detritivores (Hoff et al. 1999; Altig et al. 2007). Although omnivory may impose costs in terms of reduced efficacy of detecting, handling, and assimilating prey, it may provide greater flexibility in diet choice, which could prove advantageous in response to variation in the type and availability of food resources, or the presence of competitors and/or predators (Coll and Guershon 2002).

Interactions with predators and competitors, however, not only affect the abundance of amphibian larvae but can also induce changes in the amount or type of resources consumed by tadpoles, leading to non-consumptive cascading effects on the whole community structure across various trophic levels (Miner et al. 2005). Tadpoles are very perceptive of their environment. They are capable of detecting water-borne predator cues and alarm cues from attacked conspecific tadpoles and consequently alter their behaviour and physiology by increasing refuge use, reducing activity levels and/or increasing tail depth (Werner and Anholt 1993; Van Buskirk 2001). Similarly, tadpoles respond to competitors by increasing foraging activity and altering their morphology (Relyea 2002). Environmentally induced changes in tadpoles' overall activity level, presence in the water column and use of refugia are thus widespread (Anholt and Werner 1995; Richardson 2001) and could cause changes in their diet as a consequence of shifts in microhabitat (e.g. shifts from feeding on macrophytes to increased filtration in the water column or grazing periphyton). Moreover, competitor- and predator-induced developmental shifts affect tadpoles' anatomy in ways that could be associated with changes in their diet, as gut length, oral disc size, beak width, and tooth rows vary in response to predators and competitors (Relyea and Auld 2004, 2005). Few studies, however, have studied differences in diet within local amphibian guilds (Wells 2007), and fewer still have analysed within-species variation in diet according to microhabitat variation (Schiesari et al. 2009; Whiles et al. 2010), with the exception of the dramatic polyphenism between omnivorous and carnivorous morphs in spadefoot toads (Frankino and Pfennig 2001; Martin and Pfennig 2010). Predator- or competitor-induced plastic changes in tadpole trophic ecology may be of high relevance given their prominent role in aquatic systems (Peacor and Werner 1997; Peacor and Werner 2000; Pfennig et al. 2006).

Trophic shifts in omnivorous species are known to represent a major advantage in predator-prey interactions, as they allow prey to alter their resource use to avoid encounters with predators while continuing to feed (e.g. Ruehl and DeWitt 2007; Caut et al. 2008b). Accurate assessments of the trophic relations of omnivorous species, however, require detailed information on diets and assimilation (Altig et al. 2007; Schiesari et al. 2009), which is methodologically complicated in aquatic systems. Standard methods used to study tadpole diets (e.g. foraging observations, gut contents and faecal analysis) provide detailed accounts of what tadpoles have ingested as a snapshot of a species' diet (DíazPaniagua 1985) but may not be reliable indicators of real assimilation over longer time periods (Martínez del Rio et al. 2009). These limitations of standard techniques can be overcome using stable isotopes as tracers of nutrient flow in food webs (Gannes et al. 1997).

Interpretations of stable isotope signatures depend on a series of assumptions about the relationship between isotope ratios of consumers and their food resources (Gannes et al. 1997; Caut et al. 2008a). Isotopic signatures of C $\left(\delta^{13} \mathrm{C}\right)$ are preserved from the source through the food chain (e.g. origin), whereas $\mathrm{N}$ signatures $\left(\delta^{15} \mathrm{~N}\right)$ become enriched following transfer to a higher trophic level (Martínez del Rio et al. 2009). Isotope ratios account for temporal variance in resource assimilation over time because the diet isotopes require time to become assimilated into the consumer's tissue (turnover rate).

A difficulty in using isotopic models for evaluating incorporation of resources from different diets is that consumer metabolic processes may discriminate between different isotopes; their isotopic ratio may not exactly correspond to the isotopic ratio of the food resource. The difference in isotopic composition between any tissue of an animal (e.g. muscle and liver) and its diet is represented by a discrimination factor $(\Delta)$. Isotopic discrimination factors may differ widely among consumer classes (Caut et al. 2008c, 2009, 2010). Diet reconstructions rely on the use of isotopic models to derive quantitative estimates of dietary contributions from isotopically distinct components, and require precise estimates of such discrimination factors (Phillips and Gregg 2001; Caut et al. 2009). Small variations in discrimination factors can lead to large errors or meaningless results from isotopic models (Ben-David and Schell 2001; Caut et al. 2008a). A handful of studies have analysed amphibian trophic ecology through stable isotopes, assessing the trophic status of terrestrial adults and aquatic tadpoles, and even reporting ontogenetic changes in diet (Kupfer et al. 2006; Verburg et al. 2007; Jefferson and Russell 2008; Schiesari et al. 2009), but have not taken into account turnover rates and discrimination factors.

Here we tested for plastic changes in larval trophic ecology of two anuran species from southwestern Spain (Iberian green frog, Rana perezi, and Western spadefoot toad, Pelobates cultripes) in response to competitors and two types of predator using stable isotope analysis. It is key in designing sampling periodicity and interpreting isotope analyses to have estimates of discrimination factors and turnover rates specific to the study system, so we first conducted an experiment where we fed controlled diets to P. cultripes and Natterjack toad (Bufo calamita) tadpoles, hence obtaining discrimination factors and turnover rates for anuran larvae for the first time. 
Then, we conducted a microcosm experiment where we exposed tadpoles to the non-lethal presence of native dragonfly nymphs (Anax imperator) or non-native red swamp crayfish (Procambarus clarkii). Red swamp crayfish have a huge impact on aquatic systems, affecting several trophic levels as they are both primary consumers (filter-feeders and macrophyte consumers) and important predators of amphibian eggs and larvae (Geiger et al. 2005; Gherardi 2007; Cruz et al. 2008; Ficetola et al. 2011). Because anti-predator responses critically depend upon predator cue recognition, they may fail against novel invasive species (Cox and Lima 2006; Freeman and Byers 2006; Gomez-Mestre and Díaz-Paniagua 2011). We therefore hypothesized that tadpoles would alter their diet in the presence of competitors and native predators, and to a lesser extent in the presence of non-native predators.

\section{Materials and methods}

\section{Controlled diet experiment}

We conducted a controlled diet experiment on larvae of two anuran species ( $P$. cultripes and $B$. calamita) to determine our capacity to distinguish among possible alternative tadpole diets, the timeframe required for the diet to leave a detectable isotopic signature, and a range of discrimination factors for different diets. We then used this range of discrimination factors and diets as a baseline to calculate diet-dependent discrimination factors in tadpoles (for any tadpole species and diet, following Caut et al. 2009). We used four controlled diets, all based on natural resources that appear in tadpole diets in varying proportions (Díaz-Paniagua 1985). The macrophyte diet (diet M) consisted of a mixture of equal parts of three abundant aquatic plant species in the temporary ponds of Doñana Biological Reserve $\left(36^{\circ} 59^{\prime} \mathrm{N} / 6^{\circ} 27^{\prime} \mathrm{W}\right)$ in southwestern Spain, where tadpoles were collected: Myriophyllum alterniflorum, Ranunculus peltatus and Callitriche obtusangula (García Murillo et al. 2006). The algal diet (diet A) was obtained from a culture of Scenedesmus intermedius inoculated with pond water from Doñana. The resulting mixed algal culture was grown and kept in a bioreactor, a plexiglass cylinder filled with filtered pond water aerated with a constant flow and constantly illuminated. The final culture was a mixture of different algal species, including Scenedesmus intermedius, Scenedesmus securiformis, Nitzschia sp., Navicula sp., Chlamidomonas sp., Oscillatoria sp., Chlorella sp., Dyctiosphaerium sp., Volvox sp., Peridium sp. and Microcystis aeruginosa, all common in the ponds in Doñana (López et al. 1991). We obtained zooplankton samples (diet Z) by dip-netting, and these consisted of $99.8 \%$ Daphnia magna. Dead tadpoles (diet
T) were all laboratory-reared $P$. cultripes fed macrophytes from a prior experiment that could not be released back in the field and were sacrificed and frozen the year before. All constituents of our experimental diets were obtained from ponds within the Doñana Biological Reserve. The diets were dried to constant volume (at least 4 days at $55{ }^{\circ} \mathrm{C}$ ) and ground to a fine powder.

In February 2010, we kept portions of three different clutches per species (all captured at the same stage of development and from the same pond within the Reserve) inside a climatic walk-in chamber at Estación Biológica de Doñana where they were kept in a $12 \mathrm{~h}$ light: $12 \mathrm{~h}$ dark photoperiod at $20^{\circ} \mathrm{C}$ to enhance tadpole growth. Upon reaching the free-feeding stage (Gosner stage 25; Gosner 1960), tadpoles were transferred to each of the pure diet treatments. We collected tadpoles for isotopic analysis at four different time points: at days 21, 40, 62 and 87 (day 70 in the zooplankton diet). Our design consisted of two replicates per clutch in each treatment at each sampling time, resulting in 6 replicates $\times 4$ diets $\times 4$ sampling times per species. Each replicate consisted of ten B. calamita tadpoles or five $P$. cultripes tadpoles, [except for the first sampling $\left(\mathrm{T}_{21}\right)$, when given the small tadpole sizes we had to use 15 and ten individuals for B. calamita and $P$. cultripes, respectively, to ensure enough sample for isotopic analyses]. Due to species-specific differences in size and growth rate, we raised $B$. calamita tadpoles in 1-L containers, whereas $P$. cultripes tadpoles were raised in $3-\mathrm{L}$ ones. At the beginning of the experiment $\left(T_{0}\right)$, we took a sample of 20 hatchlings of each clutch to determine the starting isotopic values. Up to that point, tadpoles had relied on yolk to grow and develop, so variation in isotopic compositions would likely reflect differences in maternal diet. Tadpoles were fed $0.5 \mathrm{~g}$ of a powdered diet every second day, as water was renewed. The containers were thoroughly cleaned to prevent algal blooming, and dead tadpoles were removed upon sight to prevent scavenging. At each sampling time, tadpoles were sacrificed by freezing and developmental stage was determined. All samples were kept at $-20{ }^{\circ} \mathrm{C}$ until analysis. The consistency of the dietary isotopic composition was investigated by measuring the isotopic signature of different diets randomly taken from the initial powder stock 5 times throughout the experiment (Table 1).

\section{Microcosm experiment}

We used a microcosm experiment to raise tadpoles of two anuran species ( $P$. cultripes and $R$. perezi) in different scenarios of competition and predator presence that could alter their trophic ecology. Due to the breeding phenology of amphibians in Doñana, B. calamita tadpoles were no longer available for this experiment and we used $R$. perezi 
Table 1 Isotopic values ( $\% \pm$ SE) of the resources in the controlled diet experiment and the microcosm experiment

\begin{tabular}{llr}
\hline Resource & \multicolumn{1}{l}{$\delta^{13} \mathrm{C}$} & \multicolumn{1}{l}{$\delta^{15} \mathrm{~N}$} \\
\hline Controlled diet & & \\
Macrophytes & $-26.16 \pm 0.04$ & $8.43 \pm 0.08$ \\
Zooplankton & $-21.50 \pm 0.05$ & $-4.27 \pm 0.07$ \\
Algae & $-19.21 \pm 1.01$ & $6.44 \pm 0.10$ \\
Dead tadpoles & $-26.66 \pm 0.07$ & \\
Microcosm & & $5.05 \pm 0.40$ \\
Macrophytes & $-26.62 \pm 0.41$ & $8.72 \pm 0.16$ \\
Zooplankton & $-18.57 \pm 0.12$ & $-4.25 \pm 0.76$ \\
Algae & $-18.41 \pm 0.94$ & $4.25 \pm 0.37$ \\
Detritus & $-27.97 \pm 0.39$ & \\
\hline
\end{tabular}

tadpoles instead. Tadpoles from this species are more likely to compete with $P$. cultripes. Moreover, using a different species also allowed us to apply the method developed in the previous experiment, which was designed to obtain discrimination factors for any tadpole species and diet (as reviewed by Caut et al. 2009). For both amphibian species, our treatments consisted of: (1) no predator, (2) the nonlethal presence of dragonfly nymphs (Anax imperator, native predators), or (3) the non-lethal presence of red swamp crayfish (Procambarus clarkii, invasive predators). An additional treatment was made with the two species together with no predator to examine the effect of competition. Microcosms were 10-L plastic buckets filled with a 2:8 mixture of pond and carbon-filtered tap water, aerated and maintained at $20^{\circ} \mathrm{C}$ and $12 \mathrm{~h}: 12 \mathrm{~h}$ light:dark photoperiod in a climatic chamber. Pond water was added as inoculum for zoo- and phytoplankton. Each bucket was also provided with $10 \mathrm{~mL}$ of a well-mixed water sample with high density of D. magna and $160 \mathrm{~g}$ of Myriophyllum alterniflorum $(80 \mathrm{~g} /$ monthly to maintain this resource throughout the experiment), planted in small plastic cups with a spoonful of pond sediment covered with small inert aquarium pebbles.

Other than tap water, all components came from Doñana Biological Reserve. Microcosms were set up 3 weeks prior to the onset of the experiment; $500 \mathrm{~g}$ of pond sediment was added to each bucket in addition to the pond water. Macrophytes and detritus in the microcosms were sampled for isotopic analyses. We collected tadpoles of a similar stage (Gosner stage 25) in April 2010 and raised them in the laboratory for 2 months prior to the beginning of the experiment and fed them a control diet (rabbit chow) in order to establish a common dietary baseline. We then randomly assigned individual tadpoles to each bucket according to treatments. Chamber shelves were treated as experimental blocks, and all treatments were represented once on each shelf, randomly positioned upon it.
Predator cages consisted of 1-L plastic cups suspended from each bucket's side, and had small holes drilled at the bottom to allow for predator cues to diffuse. Cages were empty or held either a dragonfly nymph or a red swamp crayfish, depending on the treatment. Dragonflies were substantially smaller than crayfish, and predator presence was not corrected for predator biomass and the amount of chemical or physical (water movement) stimulus was likely unbalanced in favour of the invasive predator. There were ten replicates per treatment combination, 70 experimental units in total. Dragonflies and crayfish were not fed tadpoles in their cages within the microcosms, because otherwise we would have confounded tadpole detection of predator cues (kairomones) with detection of alarm pheromones emitted by the tadpoles eaten, rendering the comparison between predator types meaningless. Instead, we held additional dragonfly nymphs and crayfish in separate housing tanks, where they were fed mosquito larvae and tadpoles or rabbit chow, respectively. Both dragonfly nymphs and crayfish were cycled from housing tanks to the experimental microcosms and back every third day. The experiment lasted until we observed tadpoles in Gosner stages 38-40. Thus, at day 52 we removed all tadpoles from the microcosms, sacrificed them by immersion in MS-222, and noted mass and developmental stage. We estimated macrophyte consumption during the experiment by weighing the remaining macrophytes in each bucket. We weighed macrophytes after removal of excess water by gently blotting them dry with filter paper and then spinning them dry with a manual centrifuge. Tadpole samples were kept at $-20{ }^{\circ} \mathrm{C}$ until analysis. Unlike macrophytes, we could not quantitatively control or monitor the consumption of detritus, algae or zooplankton.

\section{Isotopic analysis}

In the controlled diet experiment, where tadpoles were small, we were forced to use the whole body (gastrointestinal tract removed) for analysis and pooled all individuals within each bucket. When mortality was high (e.g. algal diet), we had to pool samples by clutch or treatment for a given sampling time. Given the tadpole sizes in the microcosm experiment, we analysed tail muscle and liver for $P$. cultripes but only tail muscle for $R$. perezi, since $R$. perezi tadpoles were too small for the liver to be sampled. We selected liver and muscle because their turnover rates of stable isotopes are different, which reflects a faster assimilation time for liver than for muscle (Martínez del Rio et al. 2009). Knowing the turnover rates is important in deciding a sampling scheme in the field to determine trophic shifts that may have occurred at different times. All samples were dried and ground to a fine powder. Isotopic analyses were performed using a mass spectrometer (Optima, Micromass, UK) coupled to a $\mathrm{C}-\mathrm{N}-\mathrm{S}$ elemental 
analyser (Carlo Erba, Italy). Ratios are presented as $\delta$ values (\%o), expressed relative to the Vienna Pee Dee belemnite standard and to atmospheric $\mathrm{N}_{2}$ for $\mathrm{C}$ and $\mathrm{N}$, respectively. Reference materials were IAEA-CH-6 $\left(-10.4 \%\right.$ ) and IAEA-N1 (+0.4\%o) for $\delta^{13} \mathrm{C}$ and $\delta^{15} \mathrm{~N}$, respectively. One hundred replicate assays of internal laboratory standards indicate measurement maximum errors (SD) of $\pm 0.2 \%$ and $\pm 0.15 \%$ for stable $\mathrm{C}$ and $\mathrm{N}$ isotope measurements, respectively.

Caution must be used when applying stable isotopes to tissue with high lipid contents because the low $\delta^{13} \mathrm{C}$ values in lipids compared to other tissue may bias interpretation. Although this problem may be overcome by removing lipids from tissue samples, we did not do so due to the small size of the tissue samples coupled with the anticipated loss of tissue during the lipid extraction process. Post et al. (2007) proposes a general correction for lipid content when the $C: N$ ratio of the tissue being sampled is $>3.5$ for aquatic animals. Following their equation $\left(\delta^{13}\right.$ Cnormalized $=$ $\delta^{13}$ Cuntreated $\left.-3.32+0.99 \mathrm{C}: \mathrm{N}\right)$ lipid contents of the zooplankton diet were normalized. However, when working with a group of organisms that are not represented in Post et al. (2007) such as $R$. perezi and P. cultripes, lipid extraction should be used to estimate their relationship between delipidated $\delta^{13} \mathrm{C}$ and $\mathrm{C}: \mathrm{N}$. This is particularly important due to the high variation among taxonomic groups in the C:N ratio of lipid-free tissue (Sweeting et al. 2006). Hence we conducted a preliminary analysis on tadpoles (nine $R$. perezi and nine $P$. cultripes) exclusively fed on rabbit chow for 62 days, and this allowed us to compare isotopic values before and after lipid extraction (using the Folch method for lipid extraction; Folch et al. 1957). We found a significant linear relationship between delipidated $\delta^{13} \mathrm{C}$ (of the tadpole whole body without the stomach) and the $\mathrm{C}: \mathrm{N}$ ratio $\left(F_{1,16}=41.83, P>0.001, R^{2}=0.72\right)$ and we used the equation $\delta^{13}$ Cnormalized $=\delta^{13}$ Cuntreated $-1.11+0.37 \mathrm{C}: \mathrm{N}$ to normalize all tadpole $\mathrm{C}$ isotopic values.

\section{Statistical analyses}

For the controlled diet experiment, isotopic incorporation data were fitted using a Marquardt non-linear fitting routine (NLIN, SAS) using the following equation:

$y=a+b \mathrm{e}^{\mathrm{ct}}$

where $y$ is $\delta \mathrm{X}\left({ }^{13} \mathrm{C}\right.$ or $\left.{ }^{15} \mathrm{~N}\right), a$ is the value $\left(\delta \mathrm{X}_{(\infty)}\right)$ approached asymptotically, $b$ is the total change in the value following the switch in diet $\left[\delta \mathrm{X}_{(\infty)}-\delta \mathrm{X}_{(\mathrm{t})}\right], c$ is the turnover rate and $t$ is the time (days) since the switch. Turnover rate was also expressed in terms of half-life $\left(t_{1 / 2}\right)$, i.e. the time it takes for the isotopic composition of the tissue to reach a midpoint between the initial and final values: $t_{1 / 2}=(\ln 0.5) / c$. Discrimination factors between a food resource $(W)$ and a consumer $(Y)$ are described in terms of the difference in delta $(\delta)$ values using the $\Delta$ notation, where $\Delta=\delta Y-\delta W$. In the only three cases where models did not converge for isotopic $\mathrm{C}$, we estimated $\Delta$ by the means of isotopic values after 60 days of experiment (Table 2).

To test the effects of treatment on the isotopic values of muscle of the two tadpole species we performed a multivariate ANOVA on both isotopic elements together $\left(\delta^{13} \mathrm{C}\right.$ and $\delta^{15} \mathrm{~N}$ ), including species (Pelobates or Rana) and treatment [control, predator presence (native or invasive), and presence of heterospecific tadpoles] as main factors. We also included mass at the end of the experiment as a covariate and tested all possible interactions between the covariate and the main factors. The interactions with the covariate were not significant and hence we removed them from the model, keeping mass as the only covariate. Both main factors had significant effects on the dependent variables and therefore we conducted univariate analyses of covariance (ANCOVAs) for each isotopic element separately. Fisher's least significant difference (LSD) test was conducted to test for post hoc differences among groups. An additional ANCOVA was performed for Pelobates to test for differences between tissues (muscle and liver) in their response to treatments. We applied a Dunn-Sidak correction of the significance level since the muscle data for Pelobates were used twice. To test the effect of treatments on tadpole mass or developmental stage and on the amount of macrophytes consumed, we used ANOVA followed by a Fisher LSD for post hoc differences among the seven treatments. All these analyses were performed using STATISTICA 8.0 (StatSoft 2007). All tests fulfilled parametric assumptions and we applied no data transformations.

The relative isotopic contribution of the diet in microcosms was calculated using the SIAR package (Parnell et al. 2010). This model uses Bayesian inference to solve for the most likely set of dietary proportions given the isotopic ratios in a set of possible food sources and a set of consumers. As discrimination factors depend on several sources of variation (e.g. taxon, environment and tissue), diet-dependent discrimination factors $\left(\Delta^{13} \mathrm{C}\right.$ and $\left.\Delta^{15} \mathrm{~N}\right)$ for tadpoles were calculated from the controlled diet experiment by using regression equations between tadpole $\Delta^{13} \mathrm{C}$ and $\Delta^{15} \mathrm{~N}$ and their corresponding diet isotopic ratios following Caut et al. (2009).

\section{Results}

Controlled diet experiment

Mortality of tadpoles fed control diets was high, and was higher for B. calamita than for P. cultripes (mortalities for 
Table 2 Exponential equations (with $R^{2}$ ), half-life $\left(t_{1 / 2}\right)$ in days and discrimination factor $(\Delta$,

$\%$ ) for different control diets in Bufo calamita and Pelobates cultripes
We only calculated and represented parameters when the exponential/NLIN model converged. However, when the equation model did not significantly converge for isotopic $\mathrm{C}(*)$, we estimated $\Delta$ by means of isotopic values after 60 days of the experiment $Z$ zooplankton, $M$ macrophytes, $T$ dead tadpoles, $A$ algae

${ }^{\text {a }}$ For two clutches with initial $\delta^{15} \mathrm{~N}=0.87 \pm 0.21 \%$

b For one clutch with initial $\delta^{15} \mathrm{~N}=8.14 \%$

${ }^{c}$ For all three clutches together

\begin{tabular}{|c|c|c|c|c|c|c|}
\hline Diet & Equation $\left(R^{2}\right)$ & $d f_{\mathrm{n}}, d f_{\mathrm{d}}$ & $F$ & $P$ & $t_{1 / 2}$ & $\Delta$ \\
\hline \multicolumn{7}{|c|}{ Nitrogen } \\
\hline \multicolumn{7}{|c|}{ B. calamita } \\
\hline $\mathrm{Z}^{\mathrm{a}}$ & $y=13.07-13.01 \mathrm{e}-0.0423 x(0.95)$ & 2,16 & 123.86 & $<0.001$ & 16.39 & 4.35 \\
\hline $\mathrm{M}^{\mathrm{a}}$ & $y=13.54-13.08 \mathrm{e}-0.0289 x(0.95)$ & 2,15 & 121.95 & $<0.001$ & 23.98 & 5.11 \\
\hline $\mathrm{T}^{\mathrm{a}}$ & $y=8.38-7.59 \mathrm{e}-0.0479 x(0.93)$ & 2,13 & 79.07 & $<0.001$ & 14.47 & 1.95 \\
\hline $\mathrm{Z}^{\mathrm{b}}$ & $y=12.90-4.92 \mathrm{e}-0.0552 x(0.74)$ & 2,6 & 5.58 & 0.070 & 12.56 & 4.18 \\
\hline $\mathrm{M}^{\mathrm{b}}$ & $y=12.37-4.15 \mathrm{e}-0.0392 x(0.96)$ & 2,6 & 43.28 & 0.002 & 17.68 & 3.94 \\
\hline $\mathrm{T}^{\mathrm{b}}$ & $y=10.36-2.34 \mathrm{e}-0.0446 x(0.63)$ & 2,6 & 3.43 & 0.136 & 15.54 & 3.93 \\
\hline \multicolumn{7}{|c|}{ P. cultripes } \\
\hline $\mathrm{Z}$ & $y=12.90-11.39 \mathrm{e}-0.0422 x(0.95)$ & 2,26 & 208.56 & $<0.001$ & 16.43 & 4.18 \\
\hline M & $y=13.83-12.55 e-0.0150 x(0.90)$ & 2,23 & 92.97 & $<0.001$ & 46.21 & 5.40 \\
\hline $\mathrm{T}$ & $y=7.57-5.90 \mathrm{e}-0.0577 x(0.79)$ & 2,24 & 40.23 & $<0.001$ & 12.01 & 1.14 \\
\hline A & $y=-6.58+8.58 \mathrm{e}-0.0108 x(0.70)$ & 2,13 & 12.78 & 0.001 & 64.18 & -2.31 \\
\hline \multicolumn{7}{|c|}{ Carbon } \\
\hline \multicolumn{7}{|c|}{ B. calamita } \\
\hline $\mathrm{Z}^{\mathrm{a}}$ & $y^{\mathrm{c}}=-20.30-3.64 \mathrm{e}-0.0754 x(0.85)$ & 2,22 & 59.45 & $<0.001$ & 9.19 & -1.73 \\
\hline M & & & & & & $2.33 *$ \\
\hline $\mathrm{T}$ & & & & & & $0.66^{*}$ \\
\hline \multicolumn{7}{|c|}{ P. cultripes } \\
\hline $\mathrm{Z}$ & $y=-19.87-3.45 \mathrm{e}-0.0282 x(0.82)$ & 2,26 & 55.28 & $<0.001$ & 24.58 & -1.3 \\
\hline M & $y=-24.66+1.51 \mathrm{e}-0.0298 x(0.72)$ & 2,23 & 26.61 & $<0.001$ & 23.25 & 1.5 \\
\hline $\mathrm{T}$ & & & & & & $0.64 *$ \\
\hline A & $y=-19.08-4.05 \mathrm{e}-0.0552 x(0.95)$ & 2,13 & 97.26 & $<0.001$ & 12.56 & 0.13 \\
\hline
\end{tabular}

Bufo and Pelobates, respectively: 63.3 and $49.3 \%$ for diet A; 34.4 and $24.7 \%$ for diet M; 34.8 and $8.7 \%$ for diet Z; and 34.8 and $13.3 \%$ in diet T). There was no mortality due to the direct handling. Mortality of diet $\mathrm{Z}$ included what we suspect was an episode of toxic algal bloom in the last block of $B$. calamita, but there were enough survivors for isotopic analyses. The small size of $B$. calamita coupled with the high mortalities in treatment A prevented an isotopic analysis for that diet.

We analysed the differences in initial isotopic values among clutches to know whether we should do a fit for every clutch or if we could group similar clutches together. Overall, there were few differences in $\mathrm{N}$ and $\mathrm{C}$ isotopic values among clutches within species $(<0.5 \%$ o), with the exception of $\mathrm{N}$ in $B$. calamita, where we found an eightfold difference for one clutch (clutch $_{1} \delta^{15} \mathrm{~N}=1.1 \%$, clutch $_{2}$ $\delta^{15} \mathrm{~N}=0.7 \%$ and clutch $_{3} \delta^{15} \mathrm{~N}=8.1 \%$ ). Given this difference, we fitted the data from this clutch separately from the data for the other two clutches before performing the analysis of isotopic incorporation (see Fig. 1).

We fitted an exponential model for the whole body $\delta^{15} \mathrm{~N}$ for all diets and species. For $\delta^{13} \mathrm{C}$, the exponential model fitted significantly for all diets in $P$. cultripes but only for diet $\mathrm{Z}$ in $B$. calamita, probably due to the low $\mathrm{C}$ isotopic difference between the initial clutch values and diet- induced ones (Table 2; Fig. 1). $\mathrm{N}$ and $\mathrm{C}$ half-lives were in the same range for the two species and diets (except for the $\mathrm{N}$ half-life in diet $\mathrm{A}$ ), averaging $\sim 15-20$ days (Table 2; Fig. 1). All tadpoles were enriched in ${ }^{15} \mathrm{~N}$ and ${ }^{13} \mathrm{C}$ relative to their diet (excluding $\operatorname{diet} \mathrm{A}$ for $\mathrm{N}$ and $\operatorname{diet} \mathrm{Z}$ for $\mathrm{C}$; Table 2). $\Delta^{15} \mathrm{~N}$ and $\Delta^{13} \mathrm{C}$ was more similar between species (or among clutches) than among diets. $\Delta^{15} \mathrm{~N}$ mean in tadpoles was $3.80 \pm 0.46 \%$, with $3.91 \pm 0.61 \%$ or $B$. calamita and $3.57 \pm 1.26 \%$ for $P$. cultripes. Mean $\Delta^{13} \mathrm{C}$ in tadpoles was $1.19 \pm 0.31 \%$.

\section{Microcosm experiment}

Treatments had no effect on tadpole mass $\left(F_{3}, 36=1.84\right.$, $P=0.157$ and $F_{3}, 33=1.79, P=0.169$, for Pelobates and Rana, respectively), or developmental stage $\left(F_{3}, 36=\right.$ 1.13, $P=0.350$ and $F_{3}, 33=0.84, P=0.484$, for Pelobates and Rana, respectively).

$\mathrm{N}$ isotopic values in Pelobates differed between tissues $\left(F_{1,}, 68=14.89, P<0.001\right)$ and treatments $\left(F_{3,}{ }_{68}=\right.$ 19.91, $P<0.001)$ but the interaction was not significant $\left(F_{3,68}=0.02, P=0.997\right)$. Muscle values were lower than liver values for $\mathrm{N}$ (Fig. 2). Differences in $\mathrm{N}$ isotopic values among treatments were due to higher values of the crayfish treatment with respect to the other treatments $(P<0.001$ 
Fig. 1 Trends in $\delta^{15} \mathrm{~N}$ (a, b) and $\delta^{13} \mathrm{C}$ values (c, d; mean $\pm \mathrm{SE}$ ) for Pelobates cultripes and Bufo calamita (three clutches each) fed four different diets for 80 days: macrophytes (M), dead tadpoles (T), algae (A) and zooplankton (Z). One clutch of B. calamita (squares) was separated because it differed in initial $\mathrm{N}$ isotopic values compared to the other two clutches, but not in initial C isotopic values. The small size of $B$. calamita coupled with the high mortalities in treatment $\mathrm{A}$ prevented an isotopic analysis for that diet. Exponential fits are only shown when significant
Pelobates
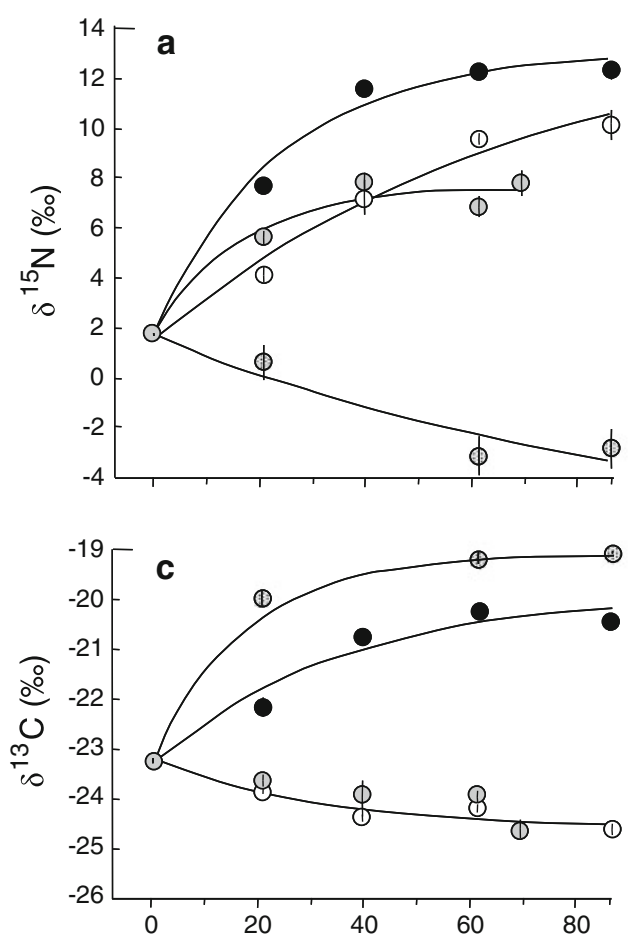

Bufo
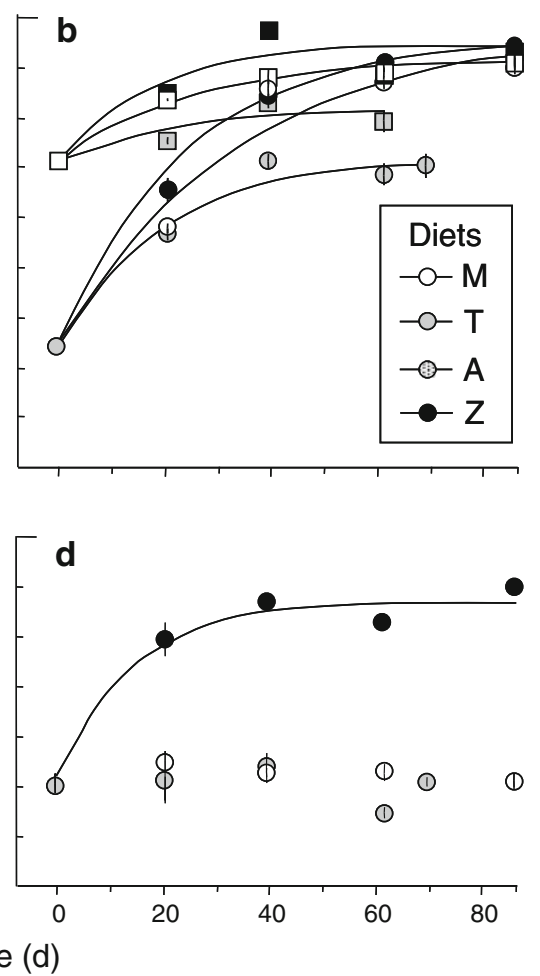
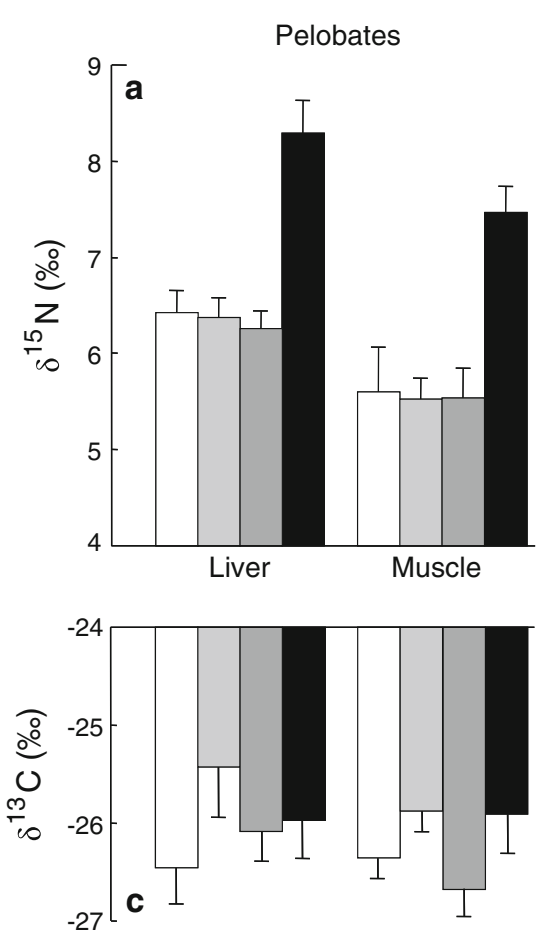
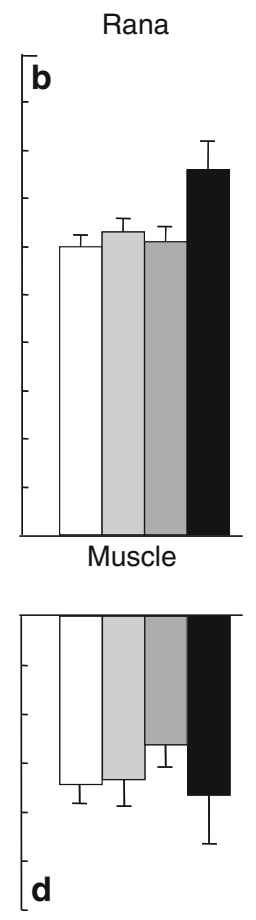

Fig. 2 a, b $\delta^{15} \mathrm{~N}$ and c, d $\delta^{13} \mathrm{C}$ values (mean $+\mathrm{SE}$ ) of Pelobates cultripes liver and muscle and Rana perezi muscle in the presence or absence of native dragonfly nymphs (Anax imperator) or the invasive predator red swamp crayfish (Procambarus clarkii), resulting in four treatments: no predator with one tadpole species (control, white bars), no predator - two species $P$. cultripes and R. perezi together (light grey bars), dragonfly predator (dark grey bars) or crayfish predator (black bars)

in all cases; Fig. 2). C isotopic values in Pelobates were similar between tissues and treatments and their interaction was not significant $(P>0.08$ in all cases).

Muscle $\mathrm{N}$ isotopic values did not vary with tadpole mass $\left(F_{1,68}=1.267, P=0.264\right)$, but differed between species (Pelobates yielded lower values than Rana; $F_{1,68}=19.23$, $P<0.001)$ and between treatments $\left(F_{3}, \quad 68=10.88\right.$, $P<0.001$ ) (Fig. 2). The species-by-treatment interaction, however, was non significant $\left(F_{3,68}=1.975, P=0.126\right)$. Both species showed higher $\mathrm{N}$ values in the presence of crayfish (Pelobates, all $P<0.001$; Rana control versus crayfish $P=0.037$; Fig. 2). Muscle $\mathrm{C}$ isotopic values did not vary with tadpole mass $\left(F_{1,68}=0.06, P=0.806\right)$. Unlike $\mathrm{N}$ values, there was no difference in $\mathrm{C}$ values between species or treatments, and there was no interaction effect.

We obtained regression equations between tadpole $\Delta^{13} \mathrm{C}$ and $\Delta^{15} \mathrm{~N}$ and their corresponding dietary isotopic ratios from the controlled diet experiment $\Delta^{13} \mathrm{C}=$ $-0.35 \delta^{13} \mathrm{C}-7.70\left(F_{1,5}=20.21, P=0.006, R^{2}=0.80\right)$; and $\Delta^{15} \mathrm{~N}=0.53 \delta^{15} \mathrm{~N}-0.37\left(F_{1,8}=38.32, P<0.001\right.$, $\left.R^{2}=0.83\right)$. These equations allowed the reliable estimation of discrimination factors $\left(\Delta^{13} \mathrm{C}\right.$ and $\left.\Delta^{15} \mathrm{~N}\right)$ of tadpoles for the various resources available in the microcosms, to inform the isotopic model SIAR. Isotopic values of the resources in microcosms are shown in Table 1.

For the two species and treatments the SIAR model (to calculate the ranges of feasible contributions for each food source) suggested that macrophytes and detritus constituted 
Fig. 3 Dietary contributions (proportion) of the four potential food sources (macrophytes, detritus, algae and zooplankton) for $P$. cultripes (a-d liver; e-h muscle) and $R$. perezi (i-l muscle) resulting in four treatments: no predator with one tadpole species (control, white bars); no predator-two species $P$. cultripes and $R$. perezi together (light grey bars); dragonfly predator (dark grey bars); or crayfish predator (black bars). Histograms show the distribution of feasible contributions from each food source to the two species' diets resulting from the application of the SIAR isotopic model.

Values shown are

5-95 percentile ranges for these distributions. Dashed line represents the mean of the distribution
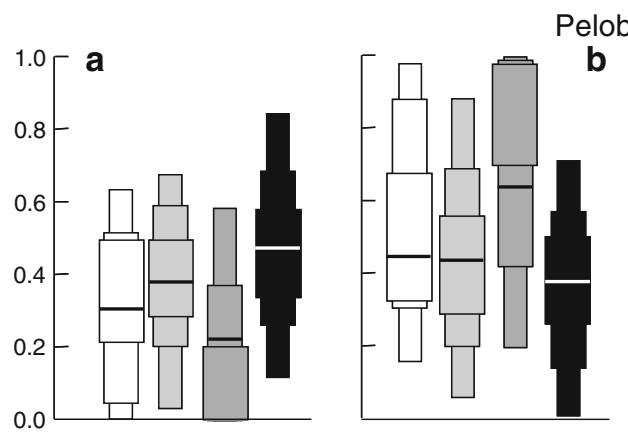

Pelobates liver

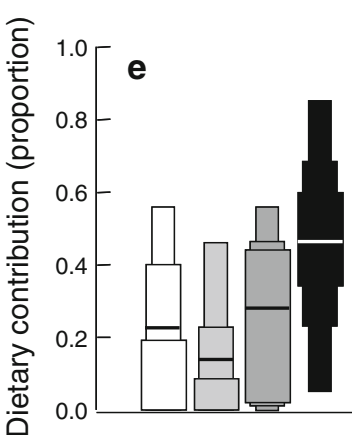

Pelobates muscle
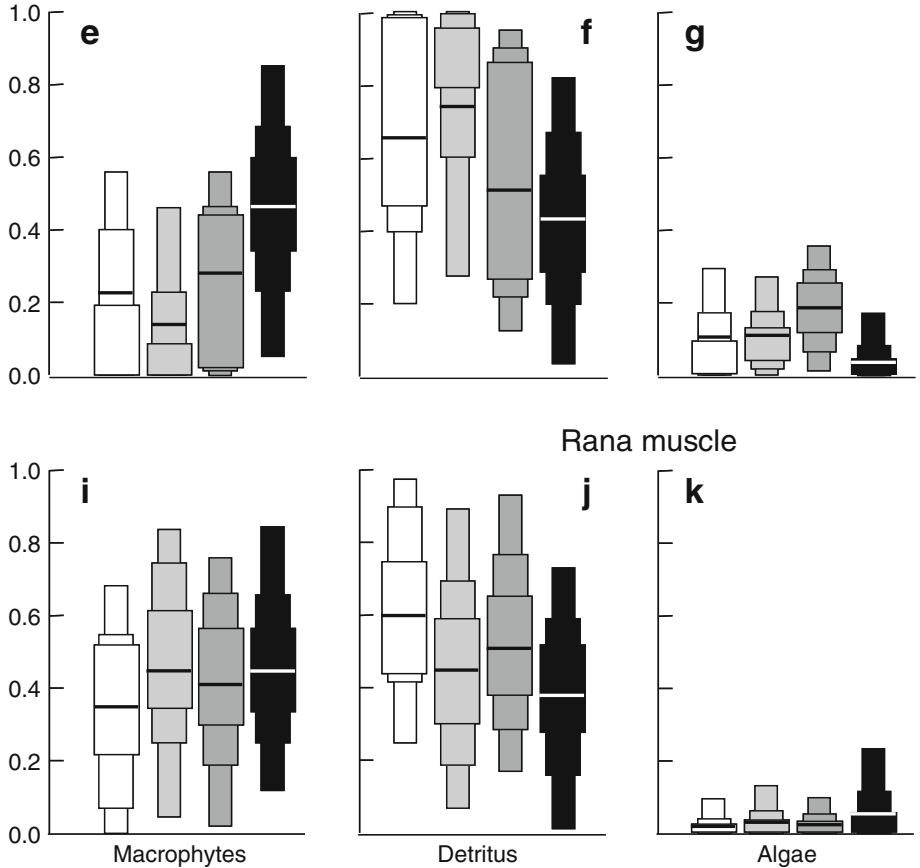

Rana muscle
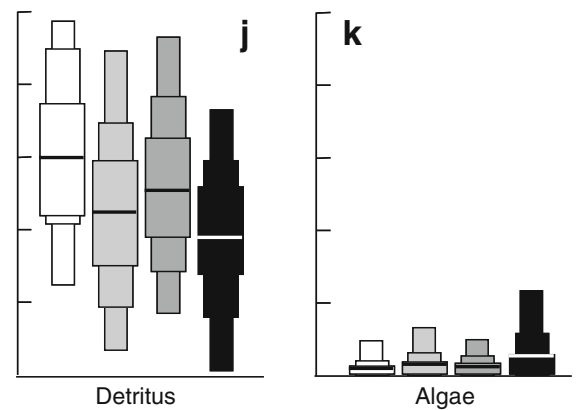
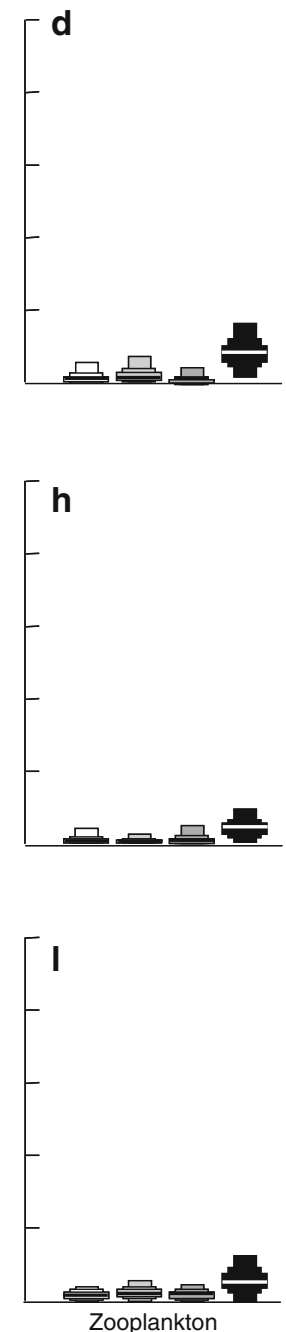

the majority of the diet, followed by algae with little contribution from zooplankton (Fig. 3). Overall, Rana showed a higher proportion of macrophytes in their diet than Pelobates, who consumed proportionately more detritus than macrophytes. In contrast, Pelobates had a greater algal contribution to its diet than Rana. Within species, tadpoles in different treatments varied in their dietary composition. In single species, combined species and dragonfly treatments, diet mostly comprised detritus (average values ranged between 45 and $70 \%$ ), macrophytes $(\sim 15-40 \%)$ and algae $(\sim 3-19 \%)$. However, in the crayfish treatment, diets of both tadpole species had a more even contribution of macrophytes $(\sim 45-50 \%)$ and detritus $(\sim 35-40 \%)$. The algal contribution tended to decrease in Pelobates and the zooplankton contribution increased in both species (Fig. 3).

The SIAR model indicated a smaller relative contribution of macrophytes to Pelobates' diet than to Rana's diet, although the actual amount of macrophyte biomass consumed was higher for Pelobates than for Rana $(P<0.016$; Fig. 4). Moreover, macrophyte consumption differed among treatments $\left(F_{6,61}=18.42, P<0.001\right.$, Fig. 4). For each species, consumption was higher when crayfish were present $(136.5 \pm 5.2 \mathrm{~g}$ for Pelobates and $78.9 \pm 9.8 \mathrm{~g}$ for Rana, respectively) than when tadpoles were alone $(106.5 \pm 7.0 \mathrm{~g}$, $P=0.008$ and $47.0 \pm 6.5 \mathrm{~g}, P=0.006$, for Pelobates and Rana, respectively) or with a native predator $(109.0 \pm$ $10.0 \mathrm{~g}, P=0.014$ and $48.3 \pm 8.2 \mathrm{~g}, P=0.009$, for Pelobates and Rana, respectively). There were no significant differences in macrophyte consumption between single tadpole species and native predator treatments $(P=0.819$ and $P=0.905$, for Pelobates and Rana, respectively). Consumption when both tadpole species were together $(105.5 \pm$ $7.3 \mathrm{~g})$ was not different to that of Pelobates alone $(P=0.927)$ or with a native predator $(P=0.749)$ but was significantly higher than in all Rana treatments $(P<0.001)$. 


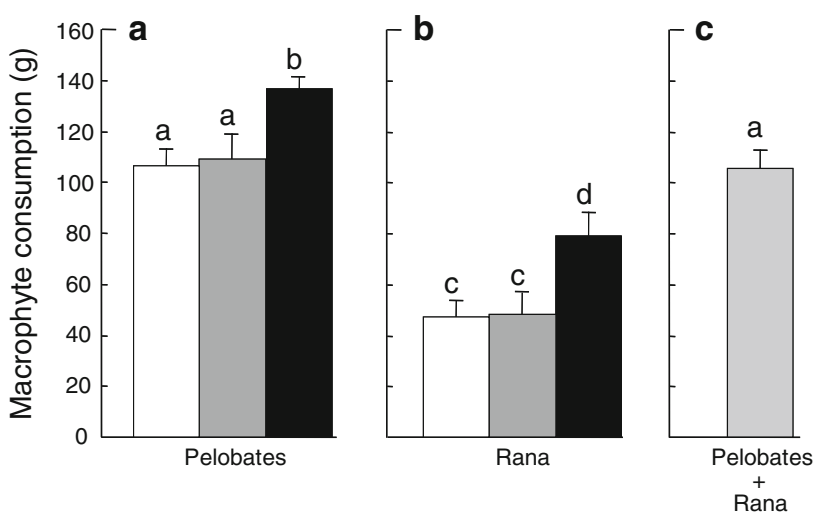

Fig. 4 Macrophyte consumption (mean + SE, difference between macrophyte mass at the beginning and at the end of the experiment) by a $P$. cultripes and $\mathbf{b} R$. perezi in the presence or absence of native dragonfly nymph (Anax imperator) or invasive predator red swamp crayfish (Procambarus clarkii). Three treatments were no predator with only one tadpole species (control, white bars), with dragonfly predator (dark grey bars) or with crayfish predator (black bars). c An additional treatment included the two tadpole species together in the absence of predators (light grey bars) to examine the potential effect of competition. Different letters indicate significant differences (Fisher's least significant difference for post hoc differences: $P<0.05)$

\section{Discussion}

Isotopic incorporation: discrimination factors and turnover rate estimation

For the first time, we quantified the dynamics of $\mathrm{N}$ and $\mathrm{C}$ isotopic incorporation in tadpoles (P. cultripes and B. calamita) via controlled feeding on pure diets. The turnover rate showed a half-life of $\sim 15-20$ days and tadpoles attained a quasi-isotopic equilibrium [nearly asymptotical values, $\left.\delta \mathrm{X}_{(\infty)}\right]$ after 2 months. This result confirms the possibility of using stable isotopes for a comparison of the trophic ecology of tadpoles in different habitats or ecological scenarios, because the isotopic equilibrium can be reached before the completion of tadpole development in a large number of species (Wells 2007).

We obtained mean $\mathrm{N}$ and $\mathrm{C}$ isotopic values for different diets that were within the range reported previously for a large array of taxa from arthropods to mammals, including tadpoles (Caut et al. 2009; Schiesari et al. 2009). Nonetheless, the range of discrimination factors was wide, especially for $\mathrm{N}$, due to differences among diets (caused by differences in protein quality, type of food and diet isotopic ratio; see Caut et al. 2008a, 2009). Hence we found that diet-dependent variation in isotopic values within amphibian species can be greater than differences across species. Therefore, assessment of the trophic status of tadpoles by comparison of their isotopic values with those of their potential food resources (e.g. Verburg et al. 2007; Jefferson and Russell 2008; Schiesari et al. 2009) is better informed by calibrating the models with respect to estimated discrimination factors (Caut et al. 2009). The wide range of discrimination factors obtained here, combined with the use of diet-dependent discrimination factors, will be a useful baseline for future research on tadpoles' trophic status in the field.

\section{Trophic plasticity in the presence of predators or competitors}

$P$. cultripes tadpoles are larger than those of $R$. perezi and had a greater overall herbivorous impact on macrophyte biomass (they consumed on average twice as much macrophyte biomass as $R$. perezi; Fig. 4), even though detritus constituted a bigger portion of their diet. Interestingly, macrophyte consumption when both tadpole species were present was no different from that of $P$. cultripes alone. This lack of additive effect on plant biomass consumption could be indicative of reduced foraging in either one of the species or both, possibly due to competition, although it was not severe enough to cause reduced growth in any of the species over the short timescale of the experiment.

Trophic status changed considerably among treatments in evidence of plasticity in the use of food resources. In contrast to our predictions, we detected a significant trophic shift (higher $\delta^{15} \mathrm{~N}$ ) in both $P$. cultripes and $R$. perezi in the presence of the non-indigenous species, the red swamp crayfish, while no changes in the diet of any of the species were observed in the presence of native dragonflies. Macrophytes, together with zooplankton, had the highest $\mathrm{N}$ isotopic values observed, suggesting that the changes in isotopic values of tadpoles were due to an increase in the relative contribution of macrophytes to the tadpoles' diet in the presence of crayfish, especially given the scarcity of zooplankton relative to macrophyte biomass, which declined throughout the experiment. This interpretation was strongly supported by actual differences among treatments in macrophyte consumption and confirmed with isotopic models.

Increased macrophyte consumption in the presence of crayfish could be interpreted as a response to perceived predation risk, as tadpoles could have sought refuge amid macrophytes and avoided the water column and open areas, hence increasing macrophyte consumption as a consequence of behavioural plasticity. However, anti-predator responses are unlikely to be the reason for increased macrophyte consumption in the crayfish treatment because $R$. perezi tadpoles from Doñana do not respond to chemical or visual cues from non-indigenous crayfish, while readily responding to dragonfly nymphs (Gomez-Mestre and Díaz-Paniagua 2011). Likewise, red swamp crayfish chemical cues do not trigger antipredator defences in P. cultripes tadpoles (Online Resource 1), and neither dragonfly nor crayfish chemical cues alone are sufficient to induce increased macrophyte consumption in P. cultripes (Online Resource 1). 
Alternatively, the observed increase in macrophyte consumption could be a response to competition from crayfish. Red swamp crayfish are important primary consumers and efficient filter feeders (Geiger et al. 2005), to the extent that a large part of their diet is composed of algae and zooplankton (Gutiérrez-Yurrita et al. 1998; Geiger et al. 2005). Although P. clarkii has a big predatory impact on amphibian guilds (Cruz et al. 2006, 2008), it is also likely that they have a dual effect as competitors too since they also feed on many of the same sources that tadpoles use (Gutiérrez-Yurrita et al. 1998; Geiger et al. 2005). The cages used in the microcosms allowed water flow, and while crayfish were prevented from accessing tadpoles or macrophytes, they were able to filter algae and zooplankton from the water column, which are important components of their diet (Geiger et al. 2005). This would be congruent with decreased algal consumption of $P$. cultripes in the crayfish treatment, although we found no such effect in $R$. perezi. Co-occurrence of both tadpole species modified the overall macrophyte consumption, but did not have an effect on the relative importance of food resources, suggesting that if competition between tadpoles occurred, it did not result in trophic segregation.

The trophic shifts observed, presumably due to competition from crayfish, may have relevant consequences for ecosystem functioning. Tadpoles constitute an important but imperiled group of consumers in freshwater habitats (Altig et al. 2007) and their feeding behaviour is often linked to functional roles, e.g. altering resource availability or quality for other consumers, (Altig et al. 2007; Whiles et al. 2010). Tadpole trophic shifts may have indirect cascading effects on the trophic structure of freshwater ecosystems. Stable isotopic analyses will help us better understand the trophic ecology of tadpoles, their role in aquatic systems and their dietary shifts in response to ecological disturbances such as the introduction of invasive species.

Acknowledgments P. Burraco, D. Cabrera and C. Pérez helped with animal husbandry. E. Costas provided advice and logistical support for algae production and identification, and M. C. Lozano helped with zooplankton identification. The authorities of Doñana National Park gave the authorization for the fieldwork. Other fieldwork facilities were provided by ICTS-RBD. This work was supported by grant CGL11123 from the Spanish Ministry of Science and Innovation, Junta Andalucía PAI group RNM 128 and co-funded by the FEDER Program CGL2009-11123. The personnel were supported by a Ramon y Cajal contract to I. G. M. (MICINN), a Juan de la Cierva contract to E. A. (MICINN) and a JAE postdoctoral contract to S. C. (CSIC).

\section{References}

Altig R, Whiles MR, Taylor CL (2007) What do tadpoles really eat? Assessing the trophic status of an understudied and imperiled group of consumers in freshwater habitats. Freshwater Biol $52: 386-395$
Anholt BR, Werner EE (1995) Interaction between food availability and predation mortality mediated by adaptive behavior. Ecology 76:2230-2234

Ben-David M, Schell DM (2001) Mixing models in analyses of diet using multiple stable isotopes: a response. Oecologia 127: 180-184

Caut S, Angulo E, Courchamp F (2008a) Caution on isotopic model use for analyses of consumer diet. Can J Zool 86:438-445

Caut S, Angulo E, Courchamp F (2008b) Dietary shift of an invasive predator: rats, seabirds and sea turtles. J Appl Ecol 45:428-437

Caut S, Angulo E, Courchamp F (2008c) Discrimination factors $(\Delta \mathrm{N}$ and $\Delta \mathrm{C}$ ) in a omnivorous consumer: the effect of diet isotopic ratio. Funct Ecol 22:255-263

Caut S, Angulo E, Courchamp F (2009) Variation in discrimination factors $\left(\Delta^{15} \mathrm{~N}\right.$ and $\left.\Delta^{13} \mathrm{C}\right)$ : the effect of diet isotopic values and applications for diet reconstruction. J Appl Ecol 46:443-453

Caut S, Angulo E, Courchamp F, Figuerola J (2010) Trophic experiments to estimate isotope discrimination factors. J Appl Ecol 47:948-954

Coll M, Guershon M (2002) Omnivory in terrestrial arthropods: mixing plant and prey diets. Annu Rev Entomol 47:267-297

Cox JG, Lima SL (2006) Naïveté and an aquatic-terrestrial dichotomy in the effects of introduced predators. Trends Ecol Evol 21:674-680

Cruz MJ, Rebelo R, Crespo EG (2006) Effects of an introduced crayfish, Procambarus clarkii, on the distribution of southwestern Iberian amphibians in their breeding habitats. Ecography 29:329-338

Cruz MJ, Segurado P, Sousa M, Rebelo R (2008) Collapse of the amphibian community of the Paul do Boquilobo Natural Reserve (central Portugal) after the arrival of the exotic American crayfish Procambarus clarkii. Herpetol J 18:197-204

Díaz-Paniagua C (1985) Larval diets related to morphological characters of five anuran species in the Biological Reserve of Doñana (Huelva, Spain). Amphib Reptil 6:307-322

Ficetola FG, Siesa ME, Manenti R, Bottoni L, De Bernardi F, PadoaSchioppa E (2011) Early assessment of the impact of alien species: differential consequences of an invasive crayfish on adult and larval amphibians. Divers Distrib 17:1141-1151

Folch J, Lees M, Stanley GHS (1957) A simple method for the isolation and purification of total lipids from animal tissues. J Biol Chem 226:497-509

Frankino WA, Pfennig DW (2001) Condition-dependent expression of trophic polyphenism: effects of individual size and competitive ability. Evol Ecol Research 3:939-951

Freeman AS, Byers JE (2006) Divergent induced responses to an invasive predator in marine mussel populations. Science 313:831-833

Gannes LZ, Obrien DM, Martínez del Rio C (1997) Stable isotopes in animal ecology: assumptions, caveats, and a call for more laboratory experiments. Ecology 78:1271-1276

García Murillo P, Fernández Zamudio R, Cirujano S, Sousa A (2006) Aquatic macrophytes in Doñana protected area (SW Spain): an overview. Limnetica 25:71-80

Geiger W, Alcorlo P, Baltanás A, Montes C (2005) Impact of an introduced Cristacean on the trophic webs of Mediterranean wetlands. Biol Invasion 7:49-73

Gherardi F (2007) Understanding the impact of invasive crayfish. In: Gherardi $F$ (ed) Biological invaders in inland waters: profiles, distribution, and threats. Springer, Dordrecht, pp 507-542

Gomez-Mestre I, Díaz-Paniagua C (2011) Invasive predatory crayfish do not trigger inducible defences in tadpoles. Proc R Soc Lond B Biol Sci 278:3364-3370

Gosner KL (1960) A simplified table for staging anuran embryos and larvae with notes on identification. Herpetologica 16: $183-190$ 
Gutiérrez-Yurrita PJ, Sancho G, Bravo MA, Baltanás A, Montes C (1998) Diet of the red swamp crayfish Procambarus clarkii in natural ecosystems of the Doñana National Park temporary fresh-water marsh (Spain). J Crustacean Biol 18:120-127

Jefferson DM, Russell W (2008) Ontogenetic and fertilizer effects on stable isotopes in the green frog (Rana clamitas). Appl Herpetol 5:189-196

Kupfer A, Langel R, Scheu S, Himstedt W, Maraun M (2006) Trophic ecology of a tropical aquatic and terrestrial food web: insights from stable isotopes (15 N). J Trop Ecol 22:469-476

Hoff KV, Blaustein AR, McDiarmid RW, Altig R (1999) Behavior: interactions and their consequences. In: McDiarmid RW, Altig R (eds) Tadpoles: the biology of anuran larvae. University of Chicago Press, Chicago, pp 215-239

López T, Toja J, Gabellone NA (1991) Limnological comparison of two peridunar ponds in the Doñana National Park (Spain). Arch Hydrobiol 120:357-378

Martin RA, Pfennig DW (2010) Field and experimental evidence that competition and ecological opportunity promote resource polymorphism. Biol J Linn Soc 100:73-88

Martínez del Rio C, Wolf N, Carleton SA, Gannes LZ (2009) Isotopic ecology ten years after a call for more laboratory experiments. Biol Rev 84:91-111

Miner BG, Sultan SE, Morgan SG, Padilla DK, Relyea RA (2005) Ecological consequences of phenotypic plasticity. Trends Ecol Evol 20:685-692

Parnell AC, Inger R, Bearhop S, Jackson AL (2010) Source partitioning using stable isotopes: coping with too much variation. PLoS ONE 5(3):e9672. doi:10.1371/journal.pone.0009 672

Peacor SD, Werner EE (1997) Trait-mediated indirect interactions in a simple aquatic food web. Ecology 78:1146-1156

Peacor SD, Werner EE (2000) Predator effects on an assemblage of consumers through induced changes in consumer foraging behavior. Ecology 81:1998-2010

Pfennig DW, Rice AM, Martin RA (2006) Ecological opportunity and phenotypic plasticity interact to promote character displacement and species coexistence. Ecology 87:769-779

Phillips DL, Gregg JW (2001) Uncertainty in source partitioning using stable isotopes. Oecologia 127:171-179

Post DM, Layman CA, Arrington DA, Takimoto G, Quattrochi J, Montana CG (2007) Getting to the fat of the matter: models, methods and assumptions for dealing with lipids in stable isotope analyses. Oecologia 152:179-189

Relyea RA (2002) Local population differences in phenotypic plasticity: predator-induced changes in wood frog tadpoles. Ecol Monogr 72:77-93

Relyea RA, Auld JR (2004) Having the guts to compete: how intestinal plastivity explains costs of inducible defenses. Ecol Lett 7:869-875

Relyea RA, Auld JR (2005) Predator- and competitor-induced plasticity: how changes in foraging morphology affect phenotypic trade-offs. Ecology 86:1723-1729

Richardson JML (2001) A comparative study of activity levels in larval anurans and response to the presence of different predators. Behav Ecol 12:51-58

Ruehl CB, DeWitt TJ (2007) Trophic plasticity and foraging performance in red drum, Sciaenops ocellatus (Linnaeus). J Exp Mar Biol Ecol 349:284-294

Schiesari L, Werner EE, Kling GW (2009) Carnivory and resourcebased niche differentiation in anuran larvae: implications for food web and experimental ecology. Freshwater Biol 54:572586

StatSoft (2007) STATISTICA (data analysis software system), version 8.0. http://www.statsoft.com

Sweeting CJ, Polunin NVC, Jennings S (2006) Effects of chemical lipid extraction and arithmetic lipid correction on stable isotope ratios of fish tissues. Rapid Commun Mass Spectrom 20:595-601

Van Buskirk J (2001) Specific induced responses to different predator species in anuran larvae. J Evol Biol 14:482-489

Verburg P, Kilham SS, Pringle CM, Lips KR, Drake DL (2007) A stable isotope study of a Neotropical stream food web prior to the extirpation of its large amphibian community. J Trop Ecol 23:643-651

Wells KD (2007) The ecology and behavior of amphibians. University of Chicago Press, Chicago

Werner EE, Anholt BR (1993) Ecological consequences of the tradeoff between growth and mortality rates mediated by foraging activity. Am Nat 142:242-272

Whiles MR, Gladyshev MI, Sushchik NN, Makhutova ON, Kalachova GS, Peterson SD, Regester KL (2010) Fatty acid analyses reveal high degrees of omnivory and dietary plasticity in ponddwelling tadpoles. Freshwater Biol 55:1533-1547 